\title{
Application of game theory when taking decisions and choosing the best variant
}

\author{
Natalya Petrikeeva ${ }^{1, *}$, Yekaterina Kopytina $^{1}$, Galina Martynenko ${ }^{1}$, Victoria Kozlova ${ }^{1}$ \\ ${ }^{1}$ Voronezh State Technical University, 84, 20-Letiya Octyabrya Street, 394006, Voronezh, Russia
}

\begin{abstract}
The paper is devoted to a new way of determining optimal distribution of resources in performing construction and assembly work. Properly analyzed territorial features of the construction site, the local topography and housing density, the degree of the system reliability, available resources, and options for carrying out work may help reduce construction costs. That may be done after choosing the best variant relying on a number of criteria, which is one of the main goals for any organization and one of the main principles of efficient use of resources. As a simulation of this situation, it is offered to consider the theory of games. The solution of the antagonistic game in relation to the gasification of housing development by a construction and assembly organization is considered. A solution to this type of game in mixed and pure strategies is offered. The results obtained may be used for further engineering evaluation. Application of this approach at early stages of construction, namely while planning and designing, may cut energy costs, will significantly reduce the organization's expenses and decrease the project implementation time by spending a little more time for taking decision at the preliminary stage. It was shown that the reliability of the system in diverse variants meets the regulatory requirements.
\end{abstract}

\section{Introduction}

In the work of any organization, the planning stage is extremely important. This statement is especially relevant when dealing with energy resources. Properly analyzed territorial features of the construction site, the local topography and housing density, the degree of the system reliability, available resources, and options for carrying out work may help reduce construction costs. That may be done after choosing the best variant relying on a number of criteria, which is one of the main goals for any organization and one of the main principles of efficient use of resources. Construction companies and design organizations plan to carry out each work stage $[1,2]$. Game theory may be used for taking important management decisions [3, 4].

Game theory is a branch of mathematics that explores mathematical models of decision taking during a conflict, that is, during a clash of parties, when each of the parties seeks to influence development of the conflict situation in its own interests $[5,6,7]$.

\footnotetext{
* Corresponding author: petrikeeva.nat@yandex.ru
} 
Most of the papers and literature related to project management is devoted to overdue projects $[8,9]$, where design problems are analyzed involving the taxation task; and procedure of distribution of fines and profits is offered.

In the following papers, a theoretical approach to the game is indirectly present in the analysis of the main distribution problem. Thus, in $[10,11]$ analysis is carried out through determining project game connected with the given task, and through considering the corresponding core as a solution. In $[9,12]$ one of the approaches to determining cost function of a construction organization is considered to create an optimal plan for the distribution of resources between a supplier and construction sites. In [11] the problem of optimizing expenses associated with the delay in completion of works at the construction site is solved by means of the cooperative game theory, while in [8] the inverse problem is formulated related to the influence of the construction site work completed before the deadline, and degree of their influence on the final terms of the project and expenses are shown, again using cooperative game theory. As well as in [13], in this paper, delayed design tasks of matrix type and with a linear function are analyzed.

An antagonistic game is the simplest and most intuitively comprehensible when determining a strategy to minimize expenses. Let's demonstrate this technique with a realistic example.

\section{Experimental}

The construction and assembly organization won a tender for comprehensive gasification of newly built housing development. The area is characterized by high-rise buildings, individual residential buildings, and there are facilities of communal and social purposes.

At the design stage, the construction and assembly organization considered several variants for gas supply systems.

Variant 1: Ring gas supply system. Total system length $l_{1}, \mathrm{~m}$, number of gasdistributing plants $n_{1}$, pcs. The reliability of the system of this variant is ensured by cyclization of the system sections, while the length and diameters of the system sections increase, but the number of gas-distributing plants is relatively small.

Variant 2: Dead end gas supply system. Total system length $l_{2}, \mathrm{~m}$, number of gasdistributing plants $n_{2}$, pcs. The reliability of the system in this embodiment is provided by increasing the number of gas-distributing plants, but at the same time the length and diameter of the system sections are significantly reduced.

That means that the condition $l_{1}>l_{2}, n_{1}<n_{2}$ is satisfied. This tendency is characteristic of several facilities of the gasified area under development.

A gasified housing development is a large site where various versions of gasification schemes will be adopted for its various parts (Variant 1, Variant 2, or a combined scheme, respectively). Construction and assembly work will be performed in several stages. At the stage of preparation for construction and assembly works, it is necessary to determine the optimal organization strategy for the acquisition, delivery and storage of the required number of sets of gas-distributing plants and the required amount of running meters of gas and water pipes for this site based on the calculation of the minimum costs and of resource for storage and delivery of equipment.

The cost of a gas-distributing plant - $C_{1}$, rubles; the cost of 1 running meter of water and gas pipe $-C_{2}$, rubles. 
To improve the interaction between the customer and the contractor of the project, there is a need to create a tool to reflect the optimal variant of works at the construction site, taking into account the main criteria of reliability and economy in the performance of work.

To find out the optimal distribution of construction resources for the gas supply area, taking into account the required criteria of reliability and economy, an antagonistic game is considered. The purpose of this game is to determine the optimal distribution of resources between players (sites) under various types of agreements (construction conditions and requirements) between them.

The antagonistic game is set by a tuple $\langle F, D, W\rangle$, where $F, D-$ multiple game strategies, $W$ - payoff function that matches each pair of the strategies $\left(F_{i}, D_{j}\right)$. The dimension of the payoff matrix of such a game is $F \times D$. Being based on the earlier designations in the problem statement, we will designate the strategies of the construction and assembly organization in the first and second variants of gas supply systems as $F_{1}, F_{2}$, where

$$
\begin{gathered}
F_{1}=\left(n_{1}, l_{1}\right) . \\
F_{2}=\left(n_{2}, l_{2}\right) .
\end{gathered}
$$

The condition of construction sites is determined as: $D_{1}-$ high-rise development ,$D_{2}-$ detached housing. Strategy selection $F_{i}, D_{j}$ unambiguously determines the outcome of the game, and the expenses, allocated for the construction, may be defined as $w_{i j}$.

If the construction and assembly organization chooses the strategy $F_{1}$, and the construction site will be in the condition $D_{1}$, the expenses for the main materials in construction of the ring gas supply system will constitute:

$$
w_{11}=n_{1} C_{1}+l_{1} C_{2} .
$$

If the construction and assembly organization chooses the strategy $F_{1}$, and the condition of the site will be $D_{2}$, the expenses for the main materials in construction of the gas supply system in this case will constitute:

$$
w_{12}=n_{1} C_{1}+\frac{l_{1}+l_{2}}{2} C_{2} .
$$

Similarly, if the construction and assembly organization chooses a strategy $F_{2}$ when the condition of the construction site is $D_{1}$, then

$$
w_{21}=\frac{n_{1}+n_{2}}{2} C_{1}+\frac{l_{1}+l_{2}}{2} C_{2}
$$

If the condition of the construction site is $D_{2}$ and the chosen strategy of the construction and assembly organization is $F_{2}$, the expenses will amount to:

$$
w_{22}=n_{2} C_{1}+l_{2} C_{2} \text {. }
$$


The payoff matrix of this game will take the following form:

\begin{tabular}{|c|c|c|}
\hline $\mathrm{F}_{1}$ & $w_{11}$ & $w_{12}$ \\
\hline $\mathrm{F}_{2}$ & $w_{21}$ & $\mathrm{D}_{22}$ \\
\hline
\end{tabular}

\section{Evaluation}

To solve the game and to find its worth $v$, maximin strategy is used for the first variant of the gas supply system construction and minimax strategy is applied for the second variant, that is:

$$
\begin{aligned}
& v_{1}=\max _{i} \min _{j} w_{i j}, \\
& v_{2}=\min _{j} \max _{i} w_{i j} .
\end{aligned}
$$

If in applying this approach the lower and upper worth of the game coincide, the worth of the game is equal to the value of the saddle point, that is the matrix game has a solution in pure strategies. Otherwise, a mixed strategy is applied and the game is solved by the analytical method $[10,14]$.

The average expenses of the construction and assembly organization when applying optimal mixed strategy will be:

$$
x^{*}=\left(x_{1}^{*}, x_{2}^{*}\right)
$$

where $x_{1}^{*}, x_{2}^{*}$ - expenses of the organization when applying maxim in strategy 1 and minimax strategy 2 , respectively.

In this case the real condition of the construction site turns to be $D_{1}$, so the worth of the game may be determined as:

$$
w_{11} x_{1}^{*}+w_{12} x_{2}^{*}=v
$$

If the real condition of the construction site is $D_{2}$, the worth of the game will be determined as:

$$
w_{12} x_{1}^{*}+w_{22} x_{2}^{*}=v
$$

Given that $x_{1}^{*}+x_{2}^{*}=1$, we get a system of equations to determine the optimal strategy for the construction and assembly organization and the worth of the game: 


$$
\left\{\begin{array}{l}
w_{11} x_{1}^{*}+w_{12} x_{2}^{*}=v \\
w_{21} x_{1}^{*}+w_{22} x_{2}^{*}=v \\
x_{1}^{*}+x_{2}^{*}=1
\end{array}\right.
$$

Solving system of equations we find:

$$
\left\{\begin{array}{l}
x_{1}^{*}=\frac{w_{22}+w_{12}}{\left(w_{11}-w_{21}\right)+\left(w_{22}+w_{12}\right)} \\
x_{2}^{*}=\frac{w_{11}-w_{21}}{\left(w_{11}-w_{21}\right)+\left(w_{22}+w_{12}\right)} \\
v=\frac{w_{11} w_{22}+2 w_{11} w_{12}-w_{12} w_{21}}{\left(w_{11}-w_{21}\right)+\left(w_{22}+w_{12}\right)}
\end{array}\right.
$$

The optimal mixed strategy of the organization will take the following form:

$$
P^{*}=x_{1}^{*} F_{1}+x_{2}^{*} F_{2}=\frac{w_{22}+w_{12}}{\left(w_{11}-w_{21}\right)+\left(w_{22}+w_{12}\right)}\left(n_{1}, l_{1}\right)+\frac{w_{11}-w_{21}}{\left(w_{11}-w_{21}\right)+\left(w_{22}+w_{12}\right)}\left(n_{2}, l_{2}\right) \text {. }
$$

The logic of the given problem solving is presented in the diagram (Fig.1).

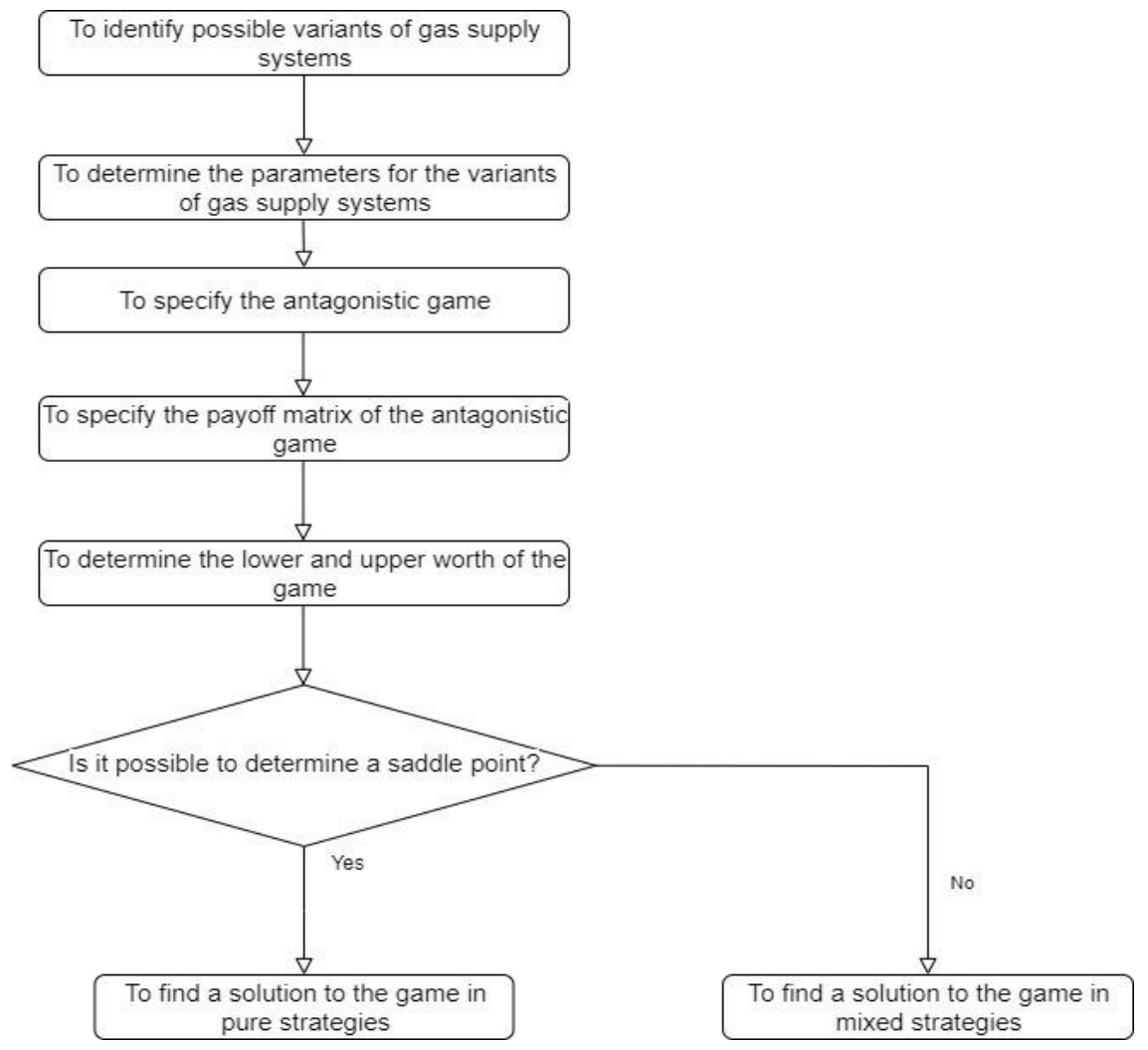

Fig. 1. The logic of the given problem solving. 


\section{Conclusions}

Thus, the construction and assembly organization should be optimally allocated for the main materials for gasification of a ring system variant

$$
\begin{aligned}
& \frac{w_{22}+w_{12}}{\left(w_{11}-w_{21}\right)+\left(w_{22}+w_{12}\right)}\left(n_{1}, l_{1}\right) \text { rubles } \\
& \text { and } \\
& \frac{w_{11}-w_{21}}{\left(w_{11}-w_{21}\right)+\left(w_{22}+w_{12}\right)}\left(n_{2}, l_{2}\right) \text { rubles }
\end{aligned}
$$

for gasification of a dead end system variant.

The work is related to optimizing a function depending on several variables. In $[11,15]$ we considered the relevance of this topic and possibility of using game theory and macro programming language for this purpose in the construction industry. It was shown that solving the problem, including when performing design and construction works, is reduced to minimizing the cost function of the design variant $[9,15]$.

The paper considers a $2 \times 2$ matrix, i.e. the number of analyzed variants is four. In practice, the number of variants considered can be much larger if for instance we take into account the material of the pipes, reassembly of their diameters, the number of gasdistributing plants, etc [16]. We considered the main, most common variants: a ring system, a dead end system and two ones combined depending on the condition of the construction site. It is assumed that a preliminary analysis of possible variants has already been carried out and these systems have been accepted for consideration. Based on this, a fundamentally new approach to solving optimization problem is offered. In the future, it will be possible to consider an expanded number of variants, but this will be implemented on the basis of a different approach.

The paper is devoted to a new approach in determining optimal allocation of resources in the construction industry, including when performing construction and assembly work. The solution of the antagonistic game in relation to the gasification of housing development by a construction and assembly organization is considered. A solution to this type of game in mixed and pure strategies is offered.

Application of this approach at early stages of construction, namely while planning and designing, will significantly reduce the organization's expenses and decrease the project implementation time by spending a little more time for taking decision at the preliminary stage. It was shown that the reliability of the system in diverse variants meets the regulatory requirements. The results obtained may be used for further engineering evaluation.

\section{References}

1. V.N. Parakhina, T.M. Fedorenko, E.Yu. Shatskaya, Teoriya organizatsii 360 (2014)

2. V.S. Abramov, S.V. Abramov, Funktsional'nye strategii 246 (2018)

3. M.A. Molchanov, Teoriya upravleniya ekonomicheskimi sistemami 307 (2018)

4. S.A. Tikhomirov, Teorija igr v praktike upravlenija i upravlencheskih kommunikacijah 1, 33-39 (2013).

5. I. N. Dubina, Osnovy teorii jekonomicheskih igr 204 (2010)

6. L.A. Petrosyan, N.A. Zenkevich, E.V. Shevkoplyas, Teoriya igr 432 (2012) 
7. A.V. Sigal, Teorija igr dlja prinjatija reshenij v jekonomike 308 (2014)

8. A.V. Kopytin, D.I. Solomatin, Ye.A. Kopytina, Vestnik Voronezhskogo gosudarstvennogo universiteta. Ser. Sistemnyj analiz i informacionnye tehnologii 4 , 119-126 (2016)

9. Ye.A. Kopytina, N.A. Petrikeeva, BIM. Proektirovanie. Stroitel'stvo. Jekspluatacija Materialy Vserossijskogo foruma 1(2), 51-55 (2018)

10. V.I. Polyakov, V.I. Skorubskiy, Osnovy teorii algoritmov 51 (2012)

11. Ye.A. Kopytina, N.A. Petrikeeva, S.G. Tul'skaja, S.N. Kuznecov, Nauchnyj zhurnal stroitel'stva i arhitektury 4(52), 137-144 (2018).

12. A.S. Garshin, Molodoy uchenyy 26, 99-102 (2017)

13. A. Estévez-Fernández, European Journal of Operational Research 3, 647-657 (2012)

14. S.I. Zakutaeva, Materialy VI Mezhdunarodnoy studencheskoy nauchnoy konferentsii Studencheskiy nauchnyy forum, https: //scienceforum.ru/2014/article/2014006276.

15. N.A. Petrikeeva, D.M. Chudinov, Ye.A. Kopytina, O.A. Sotnikova, Russian journal of building construction and architecture 4(40), 40-49 (2018).

16. V.N. Volodin, N.V. Goncharov, Russian journal of building construction and architecture 4, 2-31 (2012) 